November 1, 2010

\title{
Service Use and Costs for Persons Experiencing Chronic Homelessness in Philadelphia: A Population-Based Study
}

Stephen R Poulin, University of Pennsylvania

Marcella Maguire

Stephen Metraux, University of the Sciences in Philadelphia

Dennis P Culhane, University of Pennsylvania 
Stephen R. Poulin, M.S.W., Ph.D.

Marcella Maguire, Ph.D.

Stephen Metraux, Ph.D.

Dennis P. Culhane, Ph.D.

Objective: This study is the first to examine the distribution of service utilization and costs with a population-based sample that experienced chronic homelessness in sheltered and unsheltered locations in a large U.S. city. Methods: This study used shelter and street outreach records from a large U.S. city to identify 2,703 persons who met federal criteria for chronic homelessness during a three-year period. Identifiers for these persons were matched to administrative records for psychiatric care, substance abuse treatment, and incarceration. Results: Twenty percent of the persons who incurred the highest costs for services accounted for $60 \%$ of the total service costs of approximately $\$ 20$ million a year (or approximately $\$ 12$ million). Most of the costs for this quintile were for psychiatric care and jail stays. Eighty-one percent of the persons in the highest quintile had a diagnosis of a serious mental illness, and 83\% of the persons in the lowest quintile had a history of substance abuse treatment without a diagnosis of a serious mental illness. Conclusions: Supportive housing models for people with serious mental illness who experience chronic homelessness may be associated with substantial cost offsets, because the use of acute care services diminishes in an environment of housing stability and access to ongoing support services. However, because persons with substance use issues and no recent history of mental health treatment used relatively fewer and less costly services, cost neutrality for these persons may require less service-intensive programs and smaller subsidies. (Psychiatric Services 61:1093-1098, 2010)

$\mathrm{R}$ ecent research has demonstrated how persons with serious mental illness who are chronically homeless incur substantial service use costs. Services examined include homelessness services (shelter and outreach), general health care, mental health care, and incarceration,

but reductions in these services that are associated with supportive housing placements can offset much of the cost of providing this combination of housing and services. Initial studies that reported such findings (1-3) have led to a more generalized cost-offset model (4-6) that has served as a prototype for

Dr. Poulin is affiliated with the Center for Mental Health Policy and Services Research, University of Pennsylvania, 3535 Market St., Room 3100, Philadelphia, PA 19104 (e-mail: srp@us.net).Dr. Maguire is with the City of Philadelphia Department of Behavioral Health. Dr. Metraux is with the Department of Health Policy and Public Health, University of the Sciences, Philadelphia. Dr. Culhane is with the School of Social Policy and Practice, University of Pennsylvania, Philadelphia.
34 unpublished studies that have estimated cost reductions associated with housing placement and attendant services (7). More recent research has found significant cost reductions associated with "housing first" programs (immediate housing without requirements for sobriety, treatment session attendance, and other barriers to housing) (8-10).

Largely because of these successes in providing housing and services to this population with greater cost-efficiency than achieved with temporary shelters, the U.S. Congress and the federal government have established ending chronic homelessness as a federal priority (11). Along with this emphasis have come expectations that public costs will be reduced when chronic homelessness is ended. Such a view is predicated on the assumption that chronically homeless persons make substantial use of expensive services in the general health, mental health, and criminal justice systems. Insofar as most of the published research on cost offsets has focused on persons who have serious mental illness, chronic homelessness may have become confounded with heavy (and expensive) use of services, particularly mental health services. Were this the case, expectations about cost offsets and the provision of overly expensive support services may be unrealistic.

This study examined service use in a comprehensive population of chronically homeless individuals in a large U.S. city over a three-year period. 
This study differed from the cost studies previously referenced in that it was not restricted to those who received a supportive housing placement, many of whom were selected because of psychiatric disability or a history of heavy service use. The goal in broadening the study population was to produce a more robust and representative distribution of cumulative service use and costs associated with chronic homelessness and a more reliable baseline against which intervention costs and potential cost offsets could be projected. In addition, the population examined included a subgroup identified as chronically homeless and primarily staying in unsheltered locations. This is the first study of service use and attendant costs in this broader subgroup.

\section{Methods}

\section{Chronic homelessness data set}

Data from three administrative data sources formed the basis for an integrated database containing records for persons whose use of homelessness services was consistent with federal criteria for chronic homelessness (12). These data sources included records from a computerized database maintained by the City of Philadelphia's Office of Supportive Housing (OSH) that covers Philadelphia's municipal shelter system. Records of shelter users and shelter stays have been kept by OSH since 1990 on approximately 3,600 shelter beds, or roughly $80 \%$ of the emergency shelter services available for individuals in the City of Philadelphia $(13,14)$. Supplementing this shelter database were records from the Bethesda Project, a nonprofit organization unaffiliated with OSH that provides approximately 200 shelter beds during the winter months. The third data source was a database of homeless individuals receiving street outreach contacts through the Outreach Coordinating Center (OCC), an umbrella organization of street outreach service providers. OCC contacts are made in nonshelter locations and provide means to identify persons who are homeless but eschew shelter services. The records from these three data sources were combined through deterministic matches across data sets based on combinations of common name, gender, date of birth, and (for OSH and OCC) Social Security number. When combined, these three data sources provided information about virtually all individuals who were homeless for any substantial period in Philadelphia.

Records were selected for this study if the pattern of service use between 2000 and 2002 was consistent with the federal definition of chronic homelessness: either one year or more of continuous homelessness or at least four homeless episodes during the past three years. (The federal definition of chronic homelessness includes disability criteria that were not applied because that information was incomplete in the homelessness records for the period studied.) On the basis of this definition, a record was retained if it met one of three criteria: first, the individual's shelter intake and exit dates either spanned more than 365 days or he or she had four or more separate intakes between 2000 and 2002, each separated by 30 days of no shelter record (this definition of a shelter episode is based on a 30-day exit criterion that is based on widely used criteria [15]); second, the person entered the winter shelter program for two consecutive winter seasons; or third, the record indicated that the person had contact with homeless outreach workers either for 12 consecutive months or for four or more discrete months in the three-year observation period.

\section{Data sources on services}

The data set containing records for persons with patterns of chronic homelessness was matched to records of service use during the 2000-2002 study period that were obtained from public service systems. Deterministic matches were made with personal identifiers that were common to the database of chronically homeless persons and the sources of service records. The costs per person were tabulated by multiplying the units of services used by an estimate of the average cost per service unit. With the exception of street contacts, an annual cost per person was derived by dividing total costs by 3 .

The number of service units used came from several sources, including OSH records of shelter use, which included personal identifiers and the intake date and exit date of each shelter visit; OCC records of persons contacted in 2002, which include personal identifiers and the number of contacts made for each client; and Medicaid-reimbursed claims for behavioral health services, both inpatient and ambulatory, paid by Community Behavioral Health (CBH), a not-forprofit managed care organization contracted by the City of Philadelphia to provide mental health and substance abuse services for Philadelphia residents covered by Medicaid. The $\mathrm{CBH}$ data included personal identifiers, service dates, service type codes, and diagnoses.

Other sources of service units included inpatient and outpatient mental health services not covered by other third-party payers paid by the Office of Mental Health (OMH), which is part of Philadelphia's Department of Behavioral Health. The OMH records included personal identifiers, the provider agency, the type of service provided, and the date of service. We also used assessments, referrals, and funding support data for persons with substance abuse problems provided by the Behavioral Health Special Initiative (BHSI) for persons who were eligible for Medicaid but not enrolled. The BHSI program is operated by the City of Philadelphia's Office of Addiction Services, a component of Philadelphia's Department of Behavioral Health. The BHSI records included personal identifiers and the types and dates of inpatient and outpatient services. The final source was incarceration data in the county jail system provided by the Philadelphia Prison System, which include personal identifiers and the intake and release dates for each jail stay.

The average cost per shelter night during the 2000-2002 study period was provided by administrators at OSH. The costs per street contact were calculated by dividing an OCC estimate of the annual cost of street outreach efforts in 2002 by the annual number of contacts made during the same year. The costs per service unit for the $\mathrm{CBH}, \mathrm{OMH}$, and BHSI data were obtained by using paid 
claims to calculate the average amount paid between 2000 and 2002 for each type of service. The average cost per night of jail was created from the annual costs per night of jail published in the annual reports issued by the Philadelphia Prison System for 2000-2002.

The sample was divided into quintiles based on the total annual cost of the services the individuals had received. A comparison of these cost quintiles was the main focus of this study. The cost quintiles were compared to identify the differences in patterns of service use and clinical characteristics concerning psychiatric care and substance abuse treatment.

\section{Results}

On the basis of the aforementioned criteria, 2,703 persons exhibited patterns of chronic homelessness between 2000 and 2002. Of this total, $2,434 \quad(90.0 \%)$ persons met the chronicity criteria for shelter use only, $151(5.6 \%)$ met the criterion for use of outreach services only, and 118 $(4.4 \%)$ met both sets of chronicity criteria. Eighty-five percent of the subjects were male $(\mathrm{N}=2,298)$, and at the end of the study period (December 31,2002 ), the mean \pm SD age of this group was $43 \pm 13.45$ years.

\section{Figure 1}

Total annual costs of publicly funded behavioral health, corrections, and homelessness services, by quintile ${ }^{\mathrm{a}}$

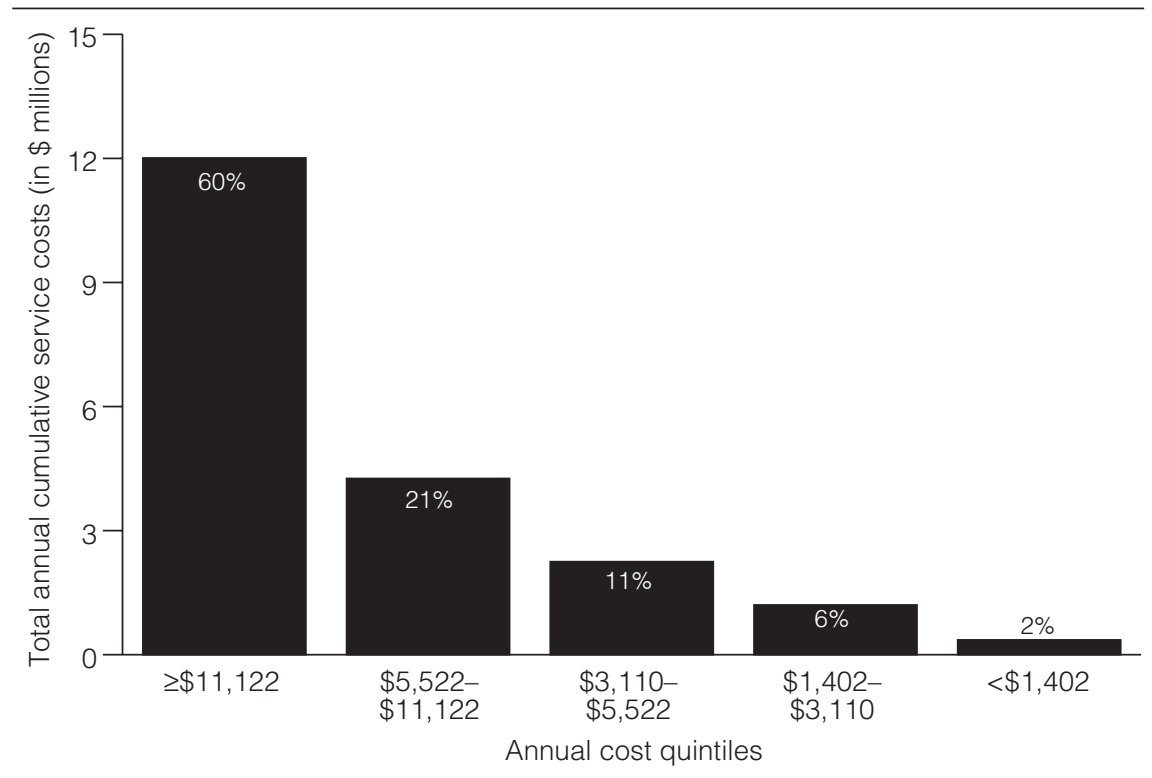

${ }^{a}$ Percentages inside bars indicate proportion of total annual service costs.

Figure 1 and Table 1 show the service costs by quintile and the total annual costs for persons tracked in this study. The quintile containing the heaviest users of services by cost collectively accounted for $60 \%$ of the total costs incurred (Figure 1), with an average annual cost of $\$ 22,372$ per person (Table 1). On average, a person who was chronically homeless used $\$ 7,455$ per year in publicly funded behavioral health, corrections, and homelessness services, which totaled approximately $\$ 20$ million annually for the chronically homeless population of Philadelphia for 2000-2002 (Table 1).

\section{Table 1}

Total annualized costs for services used by the chronically homeless population of Philadelphia in 2000-2002, by quintile

\begin{tabular}{|c|c|c|c|c|c|c|c|c|c|c|c|c|}
\hline \multirow[b]{2}{*}{ Service unit } & \multicolumn{2}{|l|}{$\begin{array}{l}\geq \$ 11,122 \\
(\mathrm{~N}=540)\end{array}$} & \multicolumn{2}{|l|}{$\begin{array}{l}\$ 5,522- \\
\$ 11,122 \\
(\mathrm{~N}=541)\end{array}$} & \multicolumn{2}{|l|}{$\begin{array}{l}\$ 3,110- \\
\$ 5,522 \\
(\mathrm{~N}=541)\end{array}$} & \multicolumn{2}{|l|}{$\begin{array}{l}\$ 1,402- \\
\$ 3,110 \\
(\mathrm{~N}=541)\end{array}$} & \multicolumn{2}{|l|}{$\begin{array}{l}<\$ 1,402 \\
(\mathrm{~N}=540)\end{array}$} & \multicolumn{2}{|l|}{$\begin{array}{l}\text { Total costs } \\
(\mathrm{N}=2,703)\end{array}$} \\
\hline & Cost $(\$)$ & $\%$ & Cost $(\$)$ & $\%$ & Cost $(\$)$ & $\%$ & Cost $(\$)$ & $\%$ & Cost $(\$)$ & $\%$ & Cost $(\$)$ & $\%$ \\
\hline Days in shelter ( $\$ 28$ per day) & $1,100,820$ & 9 & $1,417,164$ & 33 & $1,303,615$ & 58 & 873,339 & 73 & 273,177 & 76 & $4,968,115$ & 25 \\
\hline Street contacts ( $\$ 20$ per contact) & 81,940 & 1 & 64,440 & 2 & 49,780 & 2 & 40,200 & 3 & 27,540 & 8 & 263,900 & 1 \\
\hline $\begin{array}{l}\text { Visits to a crisis response center } \\
\quad(\$ 475 \text { per presentation })\end{array}$ & $1,214,417$ & 10 & 460,433 & 11 & 182,875 & 8 & 79,483 & 7 & 28,183 & 8 & $1,965,392$ & 10 \\
\hline $\begin{array}{l}\text { Case management claims ( } \$ 24 \\
\text { per } 15 \text {-minute session) }\end{array}$ & 252,520 & 2 & 51,552 & 1 & 5,392 & $<1$ & 1,032 & $<1$ & 0 & - & 310,496 & 2 \\
\hline $\begin{array}{l}\text { Psychiatric inpatient days } \\
\text { (\$468 per day) }\end{array}$ & $2,480,088$ & 21 & 526,032 & 12 & 109,356 & 5 & 34,476 & 3 & 6,396 & 2 & $3,156,348$ & 16 \\
\hline $\begin{array}{l}\text { Mental health outpatient care } \\
\quad \text { (\$68-\$75 per visit) }\end{array}$ & $3,132,320$ & 26 & 343,105 & 8 & 87,670 & 4 & 17,046 & 1 & 3,992 & 1 & $3,584,133$ & 18 \\
\hline $\begin{array}{l}\text { Substance abuse inpatient days } \\
\quad(\$ 110-\$ 300 \text { per day })\end{array}$ & 299,852 & 2 & 217,810 & 5 & 117,485 & 5 & 36,345 & 3 & 6,442 & 2 & 677,934 & 3 \\
\hline $\begin{array}{l}\text { Substance abuse outpatient care } \\
\quad(\$ 35-\$ 90 \text { per visit })\end{array}$ & 584,273 & 5 & 198,744 & 5 & 101,887 & 5 & 44,390 & 4 & 4,128 & 1 & 933,423 & 5 \\
\hline Jail ( $\$ 76$ per day) & $2,934,461$ & 24 & 981,515 & 23 & 291,460 & 13 & 75,975 & 6 & 7,651 & 2 & $4,291,061$ & 21 \\
\hline Total costs & $12,080,691$ & 100 & $4,260,795$ & 100 & $2,249,520$ & 100 & $1,202,286$ & 100 & 357,509 & 100 & $20,150,801$ & 100 \\
\hline Average cost per person & 22,372 & & 7,876 & & 4,158 & & 2,222 & & 662 & & 7,455 & \\
\hline
\end{tabular}

a Annualized reflects the average cost of services per year over the three-year period covered. 
Serious mental illness diagnoses and substance abuse indicators for the chronically homeless population of Philadelphia in 2000-2002, by quintile

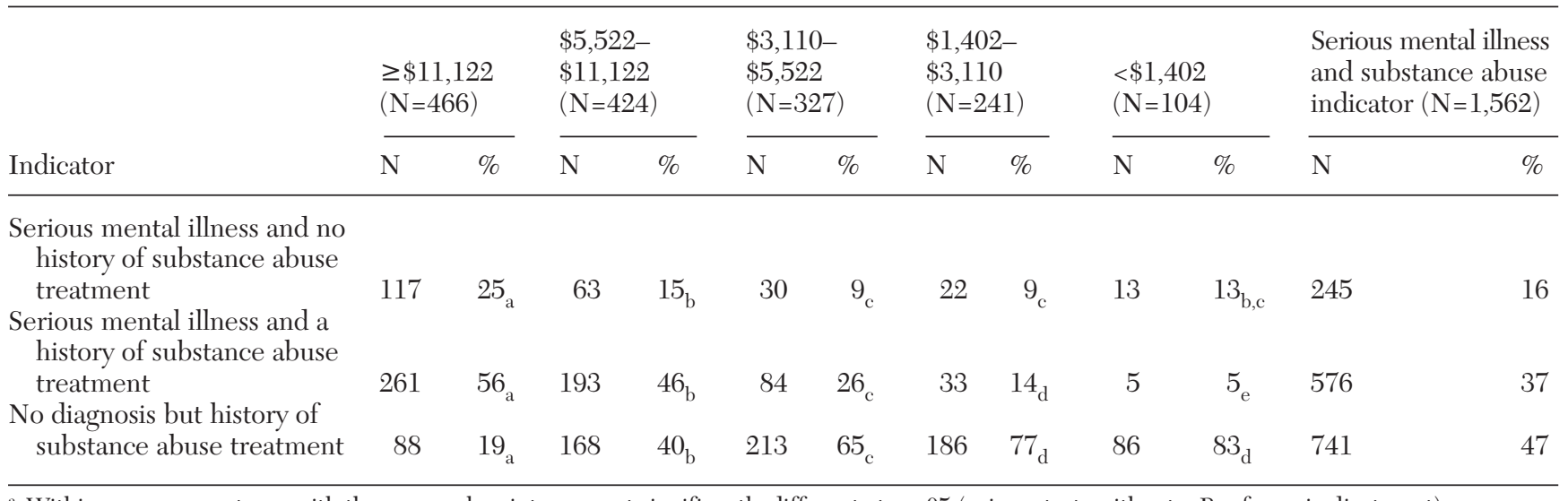

${ }^{a}$ Within rows, percentages with the same subscript were not significantly different at $\mathrm{p}<.05$ (using $\mathrm{z}$ tests without a Bonferroni adjustment).

Table 1 provides further detail regarding the sources of costs by quintile. For the most expensive quintile, $47 \%$ of the total costs tracked were for inpatient and outpatient psychiatric care. In addition, for each of the top two quintiles almost one-quarter of the total costs were from being jailed. Both as a proportion of total service use and their overall cost, psychiatric and incarceration services were used far more in these two quintiles than in the other quintiles and account for most of the overall cost differences. As the cost that each quintile represented declined, the proportions of costs for shelter use increased.

Among the 2,703 persons in the study group, 2,015 (75\%) were matched to the CBH data, and among these persons 1,562 (58\% of all the persons in the study group) had a diagnosis of serious mental illness or a history of substance abuse treatment.

\section{Table 3}

Percentages of service units for highest and lowest quintiles of the chronically homeless population of Philadelphia in 2000-2002

\begin{tabular}{lrrr}
\hline & $\begin{array}{l}\text { Service } \\
\text { units } \\
\text { used }(\mathrm{N})\end{array}$ & $\begin{array}{l}\text { Percentage of } \\
\text { all units used } \\
\text { by the sample }\end{array}$ & $\begin{array}{c}\text { Total units } \\
\text { used by } \\
\text { the sample }\end{array}$ \\
\hline Highest quintile: $\geq \$ 11,122$ & & & \\
Mental health outpatient visits & 43,306 & 87 & 49,779 \\
Case management claims (15-minute sessions) & 10,522 & 81 & 12,937 \\
Psychiatric inpatient days & 5,299 & 79 & 6,744 \\
Days in jail & 38,611 & 68 & 56,461 \\
Substance abuse outpatient care visits & 10,733 & 66 & 16,332 \\
Visits to a crisis response center & 2,557 & 62 & 4,138 \\
Substance abuse inpatient days & 1,593 & 43 & 3,711 \\
Street contacts & 4,097 & 31 & 13,195 \\
Days in shelter & 39,315 & 22 & 177,433 \\
Lowest quintile: $<$ \$, 102 & & & \\
Street contacts & 1,377 & 10 & 13,195 \\
Days in shelter & 9,756 & 5 & 177,433 \\
Visits to a crisis response center & 59 & 1 & 4,138 \\
Substance abuse inpatient days & 34 & $<1$ & 3,711 \\
Substance abuse outpatient care visits & 67 & $<1$ & 16,332 \\
Psychiatric inpatient days & 14 & $<1$ & 6,744 \\
Days in jail & 101 & $<1$ & 56,461 \\
Mental health outpatient visits & 56 & $<1$ & 49,779 \\
Case management claims (15-minute sessions) & 0 & - & 12,937 \\
& & & \\
\hline
\end{tabular}

a Sorted in descending order

A total of $821(53 \%)$ persons had any $\mathrm{CBH}$ record with a primary diagnosis of schizophrenia (ICD-9 code 295) or major affective disorder (ICD-9 code 296), the criteria used for serious mental illness; 1,317 (84\%) had a record of substance abuse treatment; and $576(37 \%)$ had a record of co-occurring serious mental illness and substance abuse treatment.

Table 2 shows that a large majority $(81 \%)$ of the persons in the highest cost quintile had a diagnosis of serious mental illness and that a nearly equal majority (83\%) of those in the lowest cost quintile had a history of substance abuse treatment without a diagnosis of serious mental illness. The prevalence of serious mental illness diagnoses among those in the highest cost quintile helps explain their exceptionally high utilization of psychiatric services. Surprisingly, the persons with a history of substance abuse treatment and no serious mental illness were prevalent in the lowest three cost quintiles.

Table 3 allows comparison of the percentages of all service units within the highest and lowest quintiles, sorted from the highest percentage of services used to the lowest. Although service utilization was expected to be higher for the highest cost quintile, the order of the services used differed for the highest and lowest cost quintiles. In addition to their extensive use of psychiatric and criminal justice services, persons in the highest cost quintile used the vast majority $(81 \%)$ 
of the case management services used by the entire sample. Although they represent only $20 \%$ of the sample, the persons in the lowest cost quintile used a substantial amount of street services (10\% of all street contacts).

\section{Discussion}

This study confirmed that chronic homelessness is costly to society, with an average annual cost for behavioral health, corrections, and homelessness services of nearly $\$ 7,500$ per person per year and a cumulative total of $\$ 20$ million annually in Philadelphia. These cost estimates are likely to understate significantly the actual public costs of chronic homelessness, because this study did not include the costs associated with police, courts, emergency medical services, and health care not associated with behavioral health. The use of general hospital care, including emergency visits, has been found to be exceptionally high among persons experiencing homelessness (1-7,9), and including the costs of such care would substantially increase the total cost of chronic homelessness.

In another key finding, most of the costs of chronic homelessness were associated with the relatively few heavy users of behavioral health inpatient care and jail. Alternatively, those with the least costs were heavy users of shelters. This suggests a substitution effect. But caution should be exercised in assuming that persons with lower total service costs will continue to consume services at a low rate, particularly as the homeless population of single adults ages. In the next decade, they will likely need more intensive medical supports (16).

Insofar as the promise of cost offsets associated with housing placement has inspired housing interventions targeting persons who are chronically homeless, this study provides some cautionary evidence. As has been noted elsewhere $(5,7)$, only the consumers with relatively higher costs of services are likely to have sufficiently high current costs to fully or mostly offset the costs of a permanent supportive housing placement, which typically costs more than $\$ 12,000$ annually $(4,9,17-19)$, including both operating subsidies and services. Unfor- tunately, it is unlikely that sufficient political will can be found to meet the ambitious federal goal of "ending chronic homelessness" without a strategy that attempts to minimize and balance costs with some degree of cost offsets, including among moderate- and lower-cost service users.

Consequently, experimentation with lower-intensity service models and less rental assistance is greatly needed. More economically efficient models of services in which the housing-specific services are transitional and the rental subsidy is permanent have been proposed, such as the critical time intervention model, which calls for transition to a communitybased care system (20-23). Given the reduction in the use of hospitals, jails, and shelters that this approach has been found to achieve and the exceptionally high utilization of psychiatric and correctional services found among the consumers with the highest service expenditure in this study, cost offsets appear to be likely.

For the others in the sample, however, either the expectation for budget neutrality will have to be changed, because costs would likely exceed cost offsets, or much less costly models of assistance will have to be considered and tested. One possibility is that users of lower-cost services may also need fewer services to attain housing stability. In particular, persons with primary substance use disorders and no co-occurring serious mental illness may be able to achieve housing stability with a modest rent subsidy, to be combined whenever possible with Supplemental Security Income (SSI) and with services provided through mainstream sources in the community. A modest rental assistance program for formerly homeless people with AIDS in New York City may be an important exemplar here (24), illustrating the value of both SSI and modest rental assistance for achieving housing stability for a large number of vulnerable adults, many with histories of injection drug use. A recent analysis provides further support for the model, showing that a modest rent subsidy to people with HIV was associated with significant reductions in homelessness (25).
Even so, it is likely that some modest net costs would accrue.

Contrary to some notions of chronic homelessness as indicative of "service resistance," it is interesting that most people in this study were engaged in some level of services with publicly funded agencies. It is striking that these service contacts were, with the exception of street contacts at $\$ 20$ per contact, more costly per unit of service (in some cases much more so) than the average cost of $\$ 22.50$ per day for an efficiency apartment in Philadelphia in 2003 (26). Such a pattern suggests that a more deliberate attempt to provide housing subsidies, even subsidies that are more modest than traditional voucher programs, deserves at least equal consideration to the funding currently allocated to health and social services.

Limitations to this study include the incompleteness in data sources, such as physical health care costs and the use of supportive housing. Moreover, some of the costs per service unit were derived from staff estimates rather than paid claims. The study included only chronically homeless persons who were not accompanied by children, consistent with the federal definition at the time of this study. Consistent with prior research, we also relied on a definition of an episode of shelter use based on the 30-day exit criterion and included any persons with four or more such episodes, regardless of the total days homeless. This definition may be overly inclusive for determining chronic homelessness, because most persons with a status of chronic homelessness were so classified on the basis of having four or more episodes of shelter use. It is unclear whether for some persons this may reflect repeated but relatively incidental (not persistent) homelessness. Future research should explore the degree to which alternative definitions of an episode (requiring 60 or 90 or 120 days of absence from shelter as indicative of the end of an episode or requiring some minimal amount of shelter use) may affect the population designated as chronically homeless and the distribution of the service use profiles. Finally, it is unclear how the study 
results, especially low rates of service contact, may be affected by persons who moved away, died, or provided false identifying informationcircumstances that could not be considered in this study.

\section{Conclusions}

Supportive housing models for people with serious mental illness who experience chronic homelessness may be associated with substantial cost offsets, because the use of acute care services diminishes in an environment of housing stability and access to ongoing support services. However, because persons with substance use issues and no recent history of mental health treatment used relatively fewer and less costly services, cost neutrality for these persons may require less service-intensive programs and more modest subsidies.

\section{Acknowledgments and disclosures}

Support for this study was provided under a contract with the City of Philadelphia's Department of Behavioral Health Services.

The authors report no competing interests.

\section{References}

1. Kushel MB, Perry S, Bangsberg D, et al: Emergency department use among the homeless and marginally housed: results from a community-based study. American Journal of Public Health 92:778-784, 2002

2. Kuno E, Rothbard AB, Averyt J, et al: Homelessness among persons with serious mental illness in an enhanced communitybased mental health system. Psychiatric Services 51:1012-1016, 2000

3. Salit SA, Kuhn EM, Hartz AJ, et al: Hospitalization costs associated with homelessness in New York City. New England Journal of Medicine 338:1734-1740, 1998

4. Culhane DP, Metraux S, Hadley TR: Public service reductions associated with the placement of homeless people with severe mental illness in supportive housing. Housing Policy Debate 13:107-163, 2002

5. Rosenheck R: Cost-effectiveness of services for mentally ill homeless people: the application of research to policy and practice.
American Journal of Psychiatry 157:15631570,2000

6. Martinez TE, Burt MR: Impact of permanent supportive housing on the use of acute care health services by homeless adults. Psychiatric Services 57:992-999, 2006

7. Culhane DP, Parker WD, Poppe B, et al: Accountability, cost-effectiveness, and program performance: progress since 1998; in Toward Understanding Homelessness: The 2007 National Symposium on Homelessness Research. Edited by Dennis D, Locke G, Khadduri J. Washington, DC, US Department of Health and Human Services, Substance Abuse and Mental Health Services Administration, and US Department of Housing and Urban Development, Office of Policy Development and Research, Sept 2007

8. Gulcur L, Stefancic A, Shinn M, et al Housing, hospitalization, and cost outcomes for homeless individuals with psychiatric disabilities participating in Continuum of Care and Housing First programmes. Journal of Community and Applied Social Psychology 13:171-186, 2003

9. Larimer ME, Malone DK, Garner MD, et al: Health care and public service use and costs before and after provision of housing for chronically homeless persons with severe alcohol problems. JAMA 301:13491357,2009

10. Gilmer TP, Manning WG, Ettner SL: A cost analysis of San Diego County's REACH Program for homeless persons. Psychiatric Services 60:445-450, 2009

11. Final FY2003 Annual Performance Plan. Washington, DC, US Department of Housing and Urban Development, 2002

12. Defining Chronic Homelessness: A Technical Assistance Guide for HUD Programs. Washington, DC, US Department of Housing and Urban Development, Office of Special Needs Assistance Programs, 2007

13. Metraux S, Culhane DP, Raphael S, et al: Assessing homeless population size through the use of emergency and transitional shelter services in 1998: results from the analysis of administrative data in nine US jurisdictions. Public Health Reports 116:344-352, 2001

14. Culhane DP, Dejowski E, Ibanez J, et al: Public shelter admission rates in Philadelphia and New York City: the implications of turnover for sheltered population counts. Housing Policy Debate 5:107-140, 1994
15. Piliavin I, Wright BRE, Mare RD: Exit and returns to homelessness. Social Service Review 70:33-57, 1996

16. Hahn JA, Kushel MB, Bangsberg DR, et al: The aging of the homeless population: fourteen-year trends in San Francisco. Journal of General Internal Medicine 21:775-778, 2006

17. Perlman J, Parvensky J: Denver Housing First Collaborative Cost Benefit Analysis and Program Outcome Report. Denver, Colorado Coalition for the Homeless, 2006

18. Hirsch E, Glasser I, D'Addabbo K, et al: Rhode Island's Housing First Program Evaluation. Providence, United Way of Rhode Island, 2008

19. Home and Healthy for Good: A Statewide Housing First Program Progress Report. Boston, Massachusetts Housing and Shelter Alliance, 2009

20. Susser E, Valencia E, Conover S, et al: Preventing recurrent homelessness among mentally ill men: a "critical time" intervention after discharge from a shelter. American Journal of Public Health 87:256-262, 1997

21. Jones K, Colson PW, Holter MC, et al: Cost-effectiveness of critical time intervention to reduce homelessness among persons with mental illness. Psychiatric Services 54:884-890, 2003

22. Draine J, Herman DB: Critical time intervention for reentry from prison for persons with mental illness. Psychiatric Services 58:1577-1581, 2007

23. Herman D, Conover S, Felix A, et al: Critical time intervention: an empirically supported model for preventing homelessness in high risk groups. Journal of Primary Prevention 28:295-312, 2007

24. Hudson Planning Group: Final Report: An Assessment of the Housing Needs of Persons With HIV/AIDS, New York City Eligible Metropolitan Statistical Area. New York, New York City Department of Health, 2004. Available at www.nyc.gov/ht $\mathrm{ml} /$ doh/downloads/pdf/ah/hiv-report-hous ing-needs.pdf

25. Dasinger LK, Speiglman R: Homelessness prevention: the effect of a shallow rent subsidy program on housing outcomes among people with HIV or AIDS. AIDS and Behavior 11(suppl):S128-S139, 2007

26. American Housing Survey for the Philadelphia Metropolitan Area: 2003. Current Housing Reports Series H170/03-33. Washington, DC, US Census Bureau, 2004 